\title{
The Global Recession as the Key Factor in the Swiss Tourism Decline
}

\author{
Igor Shcherbakovskiy
}

\author{
Lyceum Alpinum Zuoz, 217B Via S-charlattina, Zuoz, Graubünden, 7524, Switzerland
}

Email: igor-ski@yandex.ru

\section{Doi:10.5901/mjss.2015.v6n1s2p59}

\section{Abstract}

The research question investigates the famous sector of Swiss economy and the world's effect on it, especially the global recession. To determine to what extent the global recession has been the key factor in the decline of Swiss tourism, several factors in Switzerland were examined, such as the effect of global recession itself, foreign exchange, and global warming. These factors were chosen because they could have influenced tourism the most. A lot of research was done by gathering statistics from the Federal Statistical Office in Switzerland. After analysing these reports and understanding the statistics, the data for presentation and analysis in this essay was chosen. During the analysis other external sources were used to support the evidence. The analysis was based on exploring the factors that might have influenced Swiss tourism described above. Although global warming and exchange rates affected Swiss tourism, the greatest effect came from the global recession. It had a negative effect as the demand for tourism decreased during the recession from 2007 to 2009.

Keywords: global economy, recession, exchange rates, tourism, Switzerland.

\section{Introduction}

\subsection{The Context of the Research Question}

Geographically, Switzerland is a small country in the centre of Europe; however its economy is well developed. Switzerland is very small, only about half the size of Scotland. Analysis of the tourist industry within Switzerland therefore has a well-defined scope as focus stays within a fairly small realm.

Switzerland ranks 9th on the Human Development Index with a value of 0.913 (United Nations Development [UND], 2013). The Human Development index measures economic and social development by recording standard of schooling, life expectancy, and gross domestic product per capita (Blink \& Dorton, 2012). Switzerland has one of the most stable economies in the world. Political stability and financial security have made Switzerland a popular country for investors. However, because it has very limited natural resources, Switzerland has created an economy that is increasingly dependent on foreign investment.

The Swiss economy is highly based on the tertiary service sector, which occupies roughly $70 \%$ of the Swiss GDP (EconomyWatch Content [EWC], 2010). This is why tourism occupies a significant sector of the Swiss economy. Revenue from tourism in 2010 was 35.5 billion Swiss francs and tourism is the fourth biggest industry as far as exports are concerned (Swiss Tourism Federation [STF], 2012). Since the Swiss economy is highly dependent on investments coming from outside of Switzerland, the global economy has a significant influence. Many news channels such as the Economist, the Atlantic, the Washington Post, the Guardian, and the Huffington Post agree that the economies of developed countries are recovering from the 2008 economic crisis and Europe may be heading towards a double dip recession. Double dip recession is when the gross domestic product goes back to a negative value after one or two quarters of positive growth (Double-Dip Recession [DDR], 2014). It is a recession followed by short-term recovery, followed by recession again.

\subsection{The significance of the topic and why it is worthy of investigation}

This topic is significant for investigation because the tourism industry is a very important sector for Switzerland and there are possible interesting correlations, such as cross elasticity of demand theory, that will be useful for understanding the tourism industry as a whole and specific economic strategy in Switzerland. It is important to investigate the research question, because according to the hypothesis, tourism in Switzerland should decline due to the recession and strong currency. Investigation should prove or invalidate this statement and determine whether Swiss tourism might have been 
affected by factors other than global recession.

\subsection{Intended structure of the investigation}

The study will be structured according to the areas of economics that are related to the topic. Primarily, there will be an introduction to the economic concepts that will be discussed in the essay. These will include the global recession model and the value of tourism to the Swiss economy.

The essay will then go into specific details of the topic. Economic theory will be applied to tourism industries in summer and winter, global warming, business cycles, environmental concerns, and Swiss economy as a whole.

The first exploration will be based on the impact of global recession on the countries competing with Switzerland.

The second analysis will be based on exchange rate in Switzerland as it has an effect on the economy and trade. The citizenship of the biggest visitors will also be considered with regards to currency. The relationship will be investigated between the price of the Swiss franc and the demand for tourism in Switzerland.

Thirdly, the concept of Supply and Demand will be applied to the tourist industry in Switzerland.

Then, the effect of global climate change will be explored within the Swiss tourist sector in summer and in winter.

Finally, production possibility frontier theory will be applied to show the market output of Switzerland and the effect of global warming on production possibility frontiers.

There will also be a case study on one of the sport shops in St. Moritz.

This analysis should lead to a solid evaluation in the conclusion section of the extent to which the global recession has been the key factor in the decline of Swiss tourism.

\section{Methodology}

\subsection{Global recession model}

It is important to understand what a global recession is and what affects it might have on Switzerland. Recession can be defined as negative economic growth for two consecutive quarters of GDP growth (Holroyd, 2012).

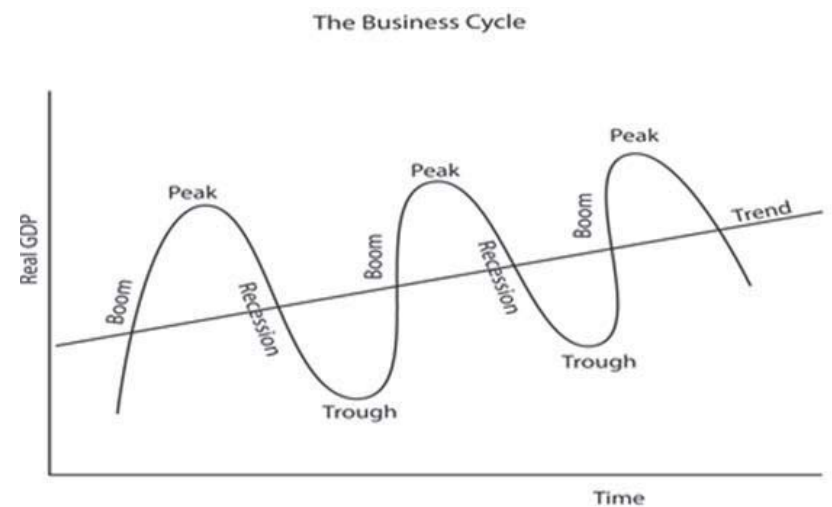

Figure 1: Business cycle

Source: Brigham Young University-Idaho, 2011. Unemployment and Inflation. Retrieved from https://courses.byui.edu/ ECON_151/Presentations/Lesson_05.htm

A business cycle is a series of expansion and contraction of economic activity within a short-term or average-length period of time (Econ, 2002). Recession symptoms show an example of a business cycle. The recession is shown on the figure 1. During recession, there is a rise in unemployment, fall in investment, business failures, and fall in expenditure. Theoretically, these effects should affect Switzerland and Swiss tourism due to the fact that foreigners who usually visit Switzerland will be less likely to invest in tourism there as well as the domestic population. However, in reality there are several other factors that affect tourism in Switzerland such as the success of advertising, weather, reports of people killed in avalanches, etc. For example, in August of 2011, there was a record 26 deaths on top of many more accidents due to hikers falling during their outdoor excursions. General safety of one's travel destination is a very important factor for any potential tourists. 


\subsection{Value of tourism to Swiss economy}

There are three types of sectors in any economy: primary, secondary and tertiary. Primary sector is related to production of raw materials. Secondary sector is where production of final goods occurs from the raw materials. Tertiary sector is the supply of final service to the consumers (Rosenberg, 2014). Tourism lies within tertiary sector. Tourism industry occupies approximately $2.9 \%$ of Switzerland's gross domestic product. In 2007 revenue from tourism in Switzerland was 14.0 billion chf. In 2011, the total revenue from tourism was 15.6 billion chf. However, there has been a decrease in revenue in the period immediately following the 2007 crash (STF, 2012). In real terms, these declines in revenue could be a result of decline in inflation after the 2007 crash. Tourist industry is generally divided into summer and winter seasons. Summer tourism includes accommodation, Nordic walking, visiting big cities, visiting zoos, mountain hiking, etc. Winter tourism includes accommodations, alpine skiing, snowboarding, visiting restaurants, etc. A large part of the tourist industry lies within the luxury sector of goods that can be validated by examining the prices of accommodation in resorts such as St. Moritz and Monteux. Therefore tourism is dependent on the wealthy population of the world.

\subsection{Impact of the global recession on the countries competing with Switzerland}

It is vital to understand the impact of global recession on competitors with Switzerland on the global market of tourism as they may be regarded as substitute goods. Substitute goods suit the same needs of consumers and can replace each other in the market and have a positive cross elasticity of demand (Substitute goods, 2013). Countries in Europe will be used because they are comparable to Switzerland in terms of travel distance, Alps, culture, etc., specifically Italy, Germany and Austria. The effect of income is the strongest in Switzerland, as the Swiss tourism industry has been steadily inclining year upon year.

Europe underwent a clear recession in 2007-2009 that affected Europe as a whole more than Switzerland (Keppel \& Wörz, 2010). During a recession with aggregate supply, there is deflation. According to the United Nations World Economic Situation and Prospects 2013 report, in Europe's recession, there was aggregate demand rather than aggregate supply. Skiing and tourism in Switzerland reflects the aggregate demand model. Deflation is a decline in prices and the rise in the value of money (Glanville \& Glanville, 2011). In the following figure a demand-side deflation shows the deflation in Europe.

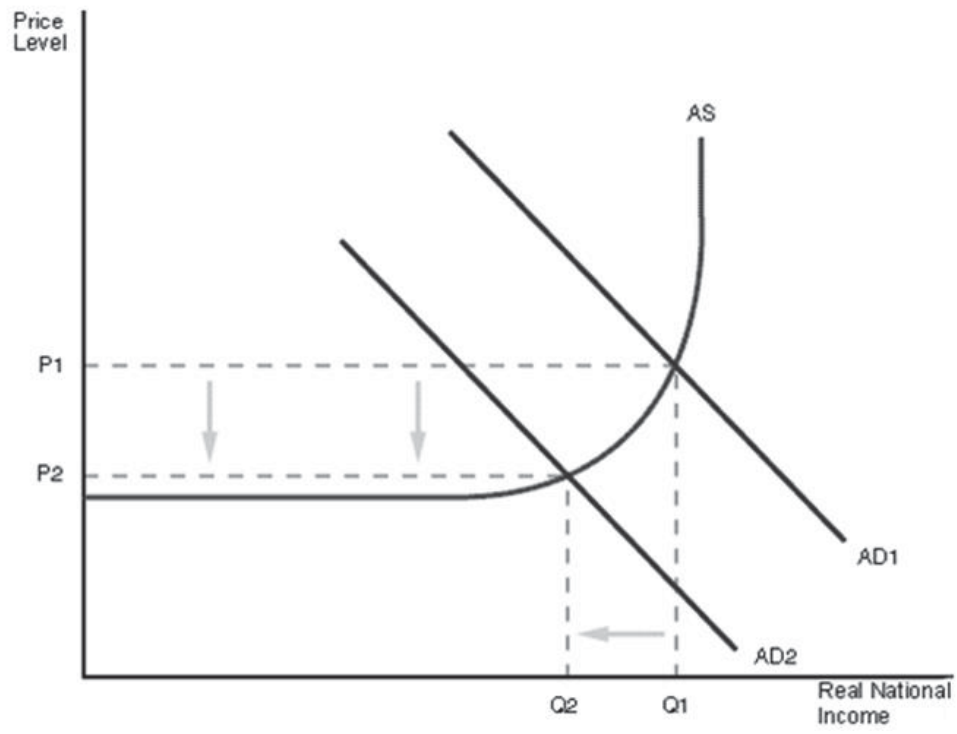

Figure 2: Deflation in Europe

Source: Deflationary Policies, 2011. Retrieved from http://www.bized.co.uk/reference/diagrams/Deflationary-Policies

The figure 2 is drawn with two axes. On the $y$-axis there is the average price level $(P)$ and on the $x$-axis there is the real output (Y). AS curve represents aggregate supply in Europe. Original aggregate demand (AD) is shown $\operatorname{as} A D_{1}$ and $A D_{2}$ shows it after the recession. Therefore it can be seen that at original equilibrium, the price was $P_{1}$ with an output of $Y_{1}$ 
and after recession the price was $\mathrm{P}_{2}$ and output $\mathrm{Y}_{2}$. This concludes that the price was deflated in the recession. This happens as a recession extends time wise, employment falls and the prices go down, as there is less aggregate demand. This type of deflation can be cured by demand-side policies aimed to increase AD.

This can be applied to compare Switzerland with other EU countries. Since Switzerland underwent a more minor recession than EU, it can be said that this had a negative effect on Swiss tourism. The Swiss tourism market declined in direct relationship to the recession and a subsequent decrease in demand. As prices deflated in EU, it became more attractive for tourists to travel there, as it is comparatively more expensive to go on holiday in Switzerland. An income effect was present in other EU countries due to the recession. This effect could mean that we will expect to see a decline in exports in Switzerland since their competition with regards to skiing and tourism remains high above other European economies.

\subsection{Exchange rates}

Understanding the Swiss franc is vital to understanding the Swiss economy. It is especially important in the tourist industry as the people coming to visit Switzerland need to buy Swiss francs. Switzerland is the second most expensive country in the world (Most Expensive Countries [MEC], 2014). Prices for tourism (hotel room rates, ski passes, etc.) are therefore higher in Switzerland than in some other countries. According to Eurostat's price level index, Switzerland's price for transportation and hotels remains high above most other European countries, at $152 \mathrm{CHF}$ for restaurants and hotels, only being surpassed by Norway at 189 NOK. Swiss currency is also the most overvalued in Europe.

However, Swiss franc appreciated even further during the recession (Strauss, Bergen \& Stalder, 2013, p. 33). Switzerland's tourism sector is mainly composed of European foreigners. (Figure 3) The Swiss economy was booming when compared to other European economies filled to the brim with debt.

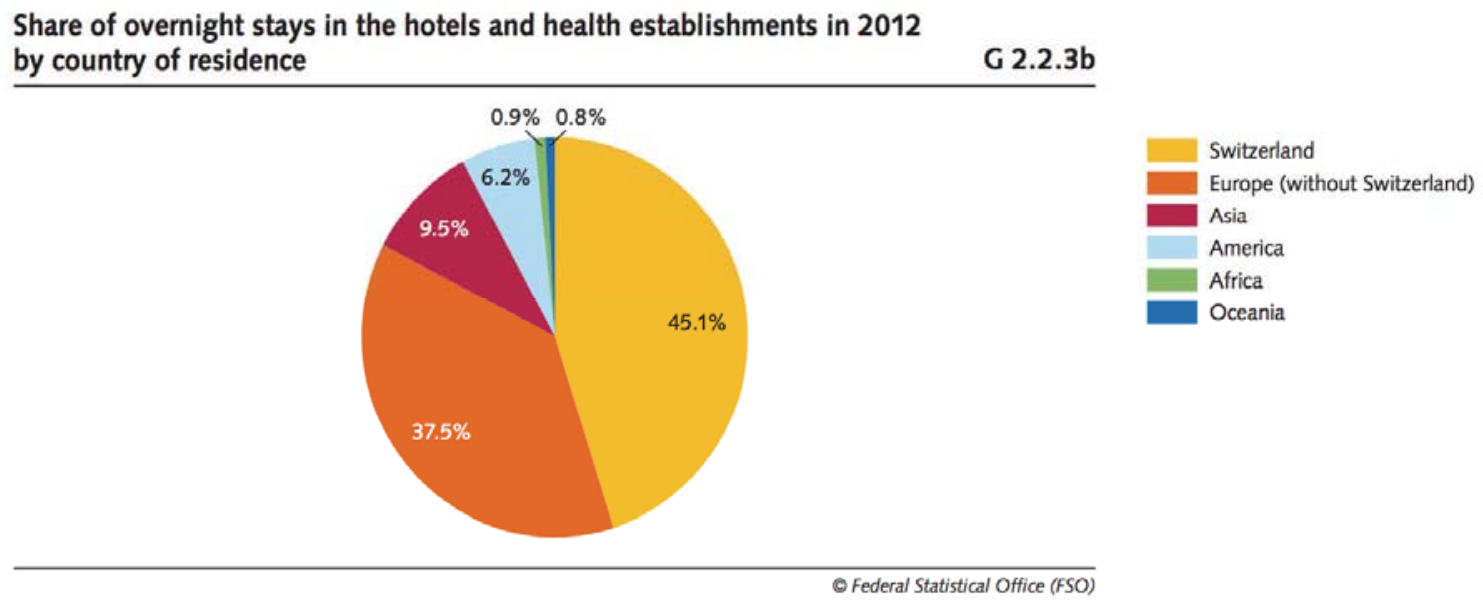

Figure 3: Switzerland's tourism sector

Source: Federal Statistical Office

The Swiss franc is very attractive for people to invest in. All around the world people want to keep their money in Swiss francs due to its stability and safety (Kuepper, 2012). Therefore, theoretically the price of the Swiss franc should rise as demand increases. Even though the GDP in 2010 grew 3.0\%, it might slow down because as the Swiss franc appreciates, it becomes more difficult for Switzerland to export, and the tourism sector is part of exports (Strauss et al. 2013, p. 53).

This is understood through supply and demand economic theory. Supply and demand is an economic concept that allows us to determine the price and quantity of a good or service in a market (Ziogas, 2008). The supply and demand figure of an expected situation with Swiss franc is shown below. 


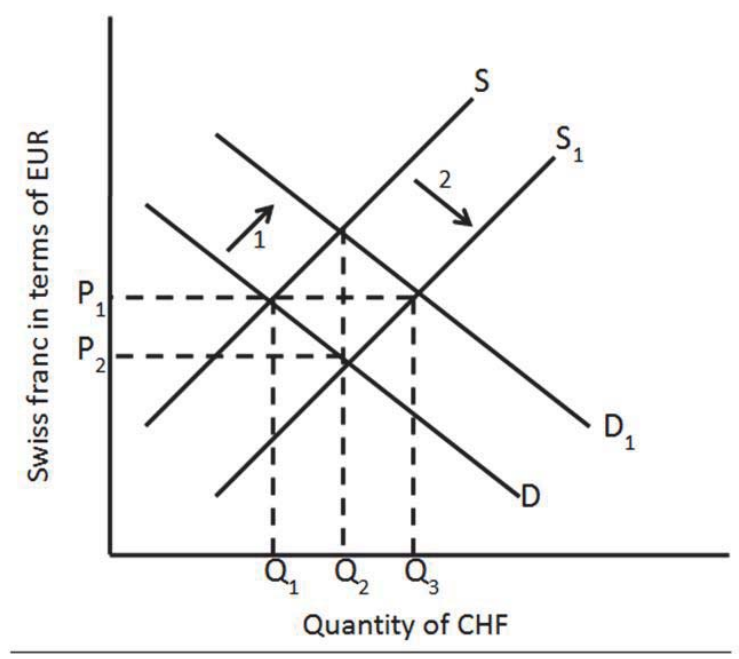

Figure 4: Demand and supply of Swiss franc

Source: designed by author

Figure 4 represents the theoretical market of the Swiss franc. The initial demand is shown by D. As people continue buying the Swiss franc, the demand for it shifts to the right, forming a new demand curve $D_{1}$. As can be seen from the figure, as the demand curve shifts to the right, the price of the Swiss franc should theoretically also increase.

However, currently the Swiss government is artificially keeping their currency stable by selling their currency as the Swiss National Bank pegged Swiss franc to Euro. This is shown by supply curve shifting to the right and the price of the Swiss franc returning to $P_{1}$. This is why the Swiss franc is kept at a stable exchange rate. At the moment the exchange rate of Swiss franc to Euro is 1.00 EUR for 1.22 CHF. The exchange rate is generally kept at 1.00 EUR: $1.20 \mathrm{CHF}$. The Swiss National Bank (SNB) set the minimum of $1.20 \mathrm{CHF}$ in September 2011 (Central bank intervenes, 2011).

There are also other currencies that are affected by the appreciation of the Swiss franc, such as US dollar and British pound. In 10 years, the US dollar has lost $38.3 \%$ of its value against the Swiss franc, British pound $37.1 \%$, the yen $24.2 \%$ (Strauss et al., 2013, p. 33). This devaluation also happened in the three years of recession that are being analysed. As the countries with these currencies represent around $46 \%$ of tourists this represents a major reason for the decline in Swiss tourism (Strauss et al., 2013, p. 10). Therefore it should be difficult for Switzerland to export holidays to countries having currencies other than Euro.

The fluctuations of exchange rates are shown in the following figure.

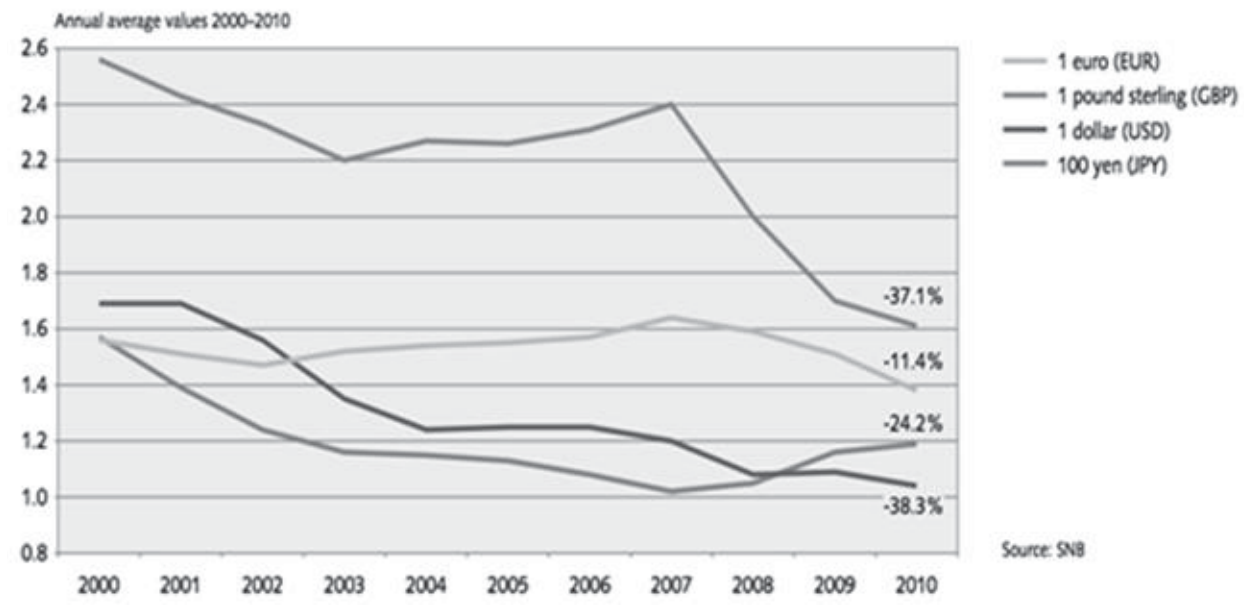

Figure 5: Change in exchange rates 2000-2010

Source: Strauss et al. 2011, 28 
As can be seen, there is a rapid increase in the value of Swiss franc against Euro, British pound, and US dollar during the global recession (starting in 2007).

Change in demand by country of residence

The exchange rate should affect the visitors that are planning to go to Switzerland for holidays. The following figures show the breakdown of the residences of the visitors coming to Switzerland between 2007 and 2011.
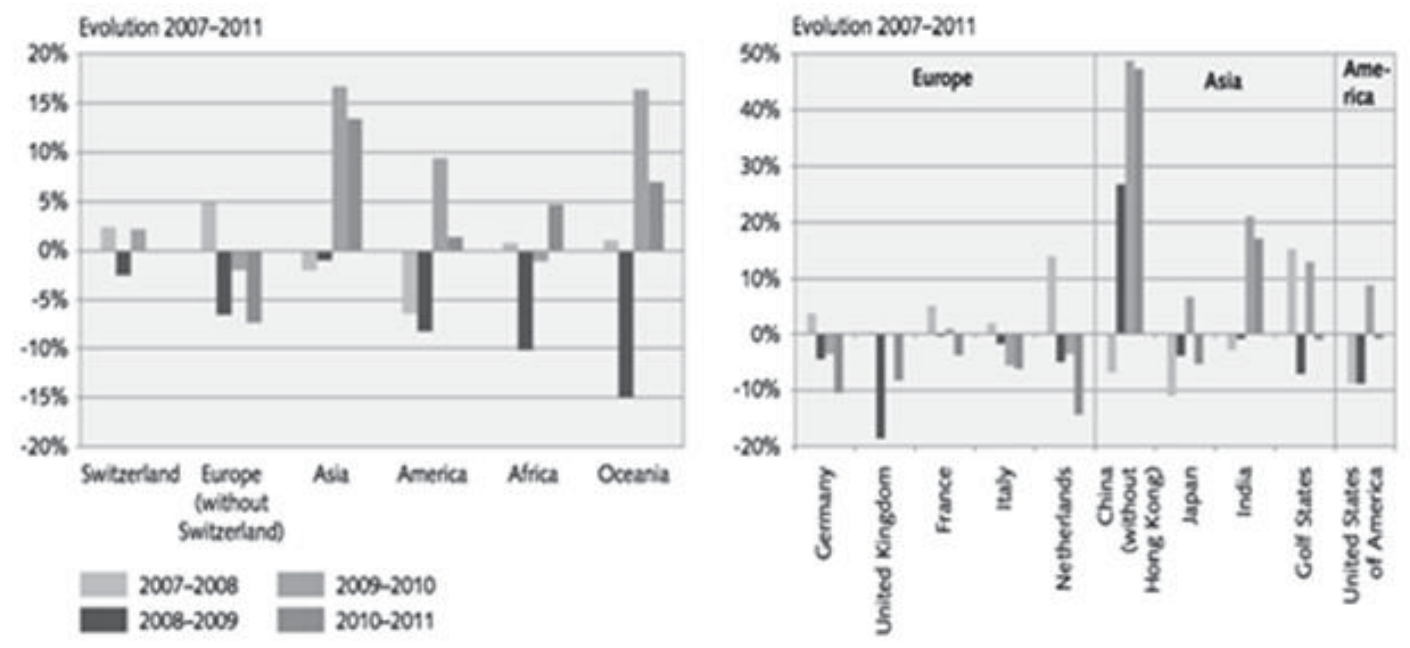

Figure 6: Overnight stays in hotels and health establishments by continent and by main countries of residence Source: Strauss et al. 2011, 15

In the figure 6, overnight stays in hotels in Switzerland and across the world can be observed in the years 2007-2008 and 2008-2009. The appreciation of Swiss franc can be one of many causes why tourism decreased during the global recession. As the pound has been devalued against the Swiss franc the most, the decrease in demand for Swiss holidays is the greatest in United Kingdom. In 2007-2008 most of the effect of appreciation of Swiss franc is seen in Asia and America. In 2008-2009 people from all continents decreased their demand for Swiss holidays. In 2010-2011 there was a general increase in demand for hotel stays. However, in Europe it had decreased even further not only due to the exchange rates. This might be due to the economic problems that face the European Union. China has increased its demand for Swiss holidays. This might be due to the fact that Chinese Yuan did not devalue against Swiss franc.

It is also important to notice that global recession led to a decrease in demand of Swiss citizens for travel in their own country. This might have happened due to fall in consumer confidence. Even though it was not a big decrease, it still influenced tourism as Swiss citizens occupy the biggest share of overnight stays in Switzerland (Figure 3).

The total output of the Swiss tourism sector should decrease, due to the fact that the demand for Swiss holidays from Europeans decreased and Switzerland's tourism industry was mostly used by Europeans. Asian people are the second biggest group to visit Switzerland and their demand also shrunk during global recession. Americans are the third biggest group to visit Switzerland and they too decreased their demand for Swiss holidays. The evolution of the composition of tourists before and after the crisis showed that Europeans still were the primary tourist demographic, followed by Asians and Americans. The share changed after the crisis, when all countries that decreased their share also experienced depreciation. This shows how the argument of appreciation of the Swiss franc becomes more valid. Depreciation of foreign currencies, then, highly relies on the Swiss currency. This is shown by changing trends within the Swiss tourism industry before and after the recession.

However, these decreases in demand might not be caused by the foreign exchange, but by other personal factors. Factors such as the recession and the expensive nature of Swiss tourism prices also might have had a deterrent effect on tourists' decisions to travel to Switzerland.

Nevertheless, a decrease in demand for hotel stays during the period of 2007-2009 is still clearly shown by the figure above.

Recently, the demand for Swiss holidays increases again, except in Europe.

Cross Price Elasticity of demand (XED)

This is another factor that can affect the output of the tourism industry and it can be related to the currency in 
Switzerland.

A factor that may have caused the demand for tourism to go down is cross elasticity of demand. Cross elasticity of demand is measuring the change in demand for one product when there is a change in the price of a corresponding product (Ziogas, 2008). The price of the Swiss franc in terms of Euros can be compared with the demand for tourism in Switzerland. Euros are used, because Europeans visit Switzerland the most as foreigners. Years 2008-2009 will be used for analysis as they show the greatest impact of the global recession.

Cross elasticity of demand is calculated by using the formula below:

$\mathrm{XED}=\frac{\text { Percentage in quantity demanded of product } \mathrm{X}}{\text { Percentage change in price of product } \mathrm{Y}}(1)$

Therefore for Swiss franc in tourism:

$\mathrm{XED}=\frac{\text { Percentage change in quantity demanded of overnight stay in hotel by Europeans }}{\text { Percentage }}$

$\mathrm{XED}=\frac{-6.5 \%}{-6.25 \%}$

$\mathrm{XED}=+1.04$

As can be seen, the answer is a positive number and therefore this good and service are related to each other. Therefore this calculation has validated that currency value changes have an effect on the demand for tourism in Switzerland. The price of tourism in Europe and the rest of the world is less than the tourism industry in Switzerland, one of the most expensive travel destinations worldwide.

Also according to this formula, overnight stays by Europeans in Swiss hotels is bolstered by the medium of an exchange rate between the Swiss franc and the Euro. The indirect effect of currency value of the Euro is shown in the above figure. The economic rationale behind this calculation is that tourism in Switzerland and the appreciation of the Swiss franc are linked and share a positive correlation.

\subsection{Supply and Demand in tourist industry}

Supply and demand theory is used to compare the demand of a resource and supply for the same resource. This theory determines the price of the good or service and quantity of the service supplied or demanded. The point where two curves cross is called equilibrium (Glanville \& Glanville, 2011). Equilibrium is the point where the market is at its full allocated efficiency and the profits at this point may be the greatest (may be below its PPF curve).

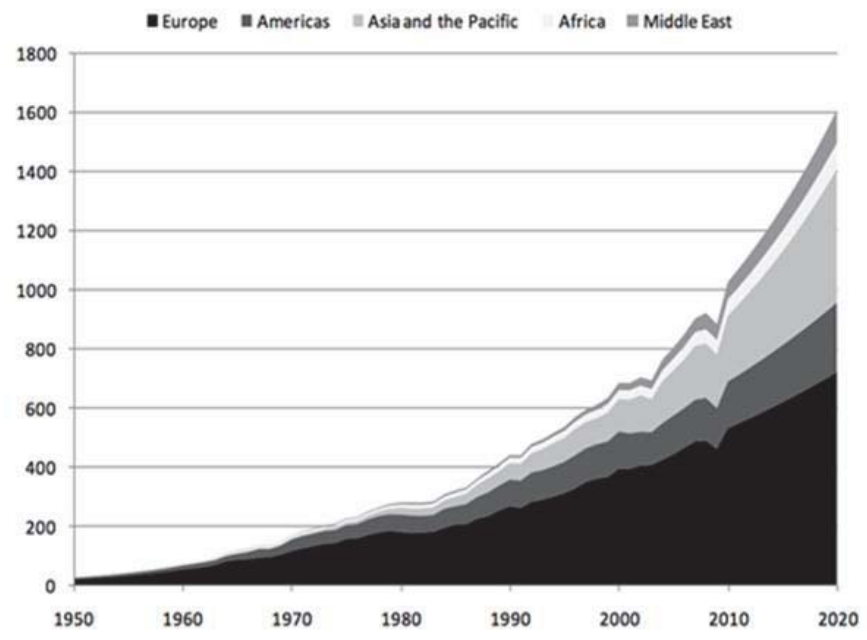

Figure 7: International tourist arrivals, 1950-2000

Source: United Nations World, 2009, 11

The figure 7 shows the tourist arrivals between 1950 and 2009 and an extrapolation to 2020. This corresponds to equilibrium quantities for tourism. It is important to concentrate on the years 2007-2009 as the global recession affected these years. There is a dip between the years 2008-2009 in all continents shown, including Switzerland. Therefore this figure serves as an overview to the global situation, which is deeply investigated for Switzerland. 


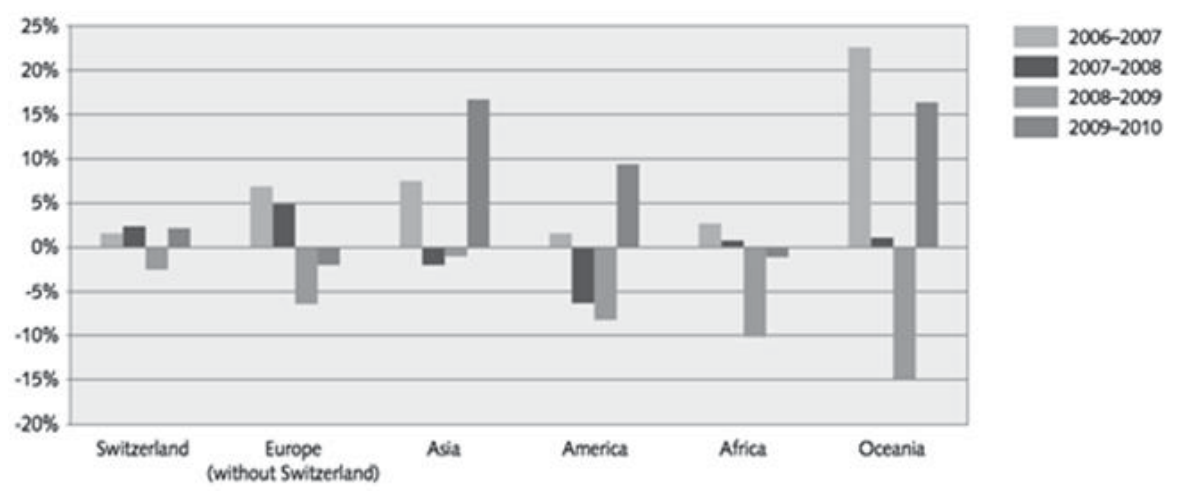

Figure 8: Hotels and Health Establishments: Change in overnight stays by continent from 2006 to 2010 Source: Strauss et al. 2011, p. 13

The figure 8 shows that Switzerland was affected by the global recession in 2008 and 2009, as there is a decrease in overnight stays between 2008 and 2009. The figure shows a small increase in overnight stays in the years 2007 and 2008 in Switzerland, Europe, Africa and Oceania. This might be due to the fact that people had already booked their holidays before the global recession began.

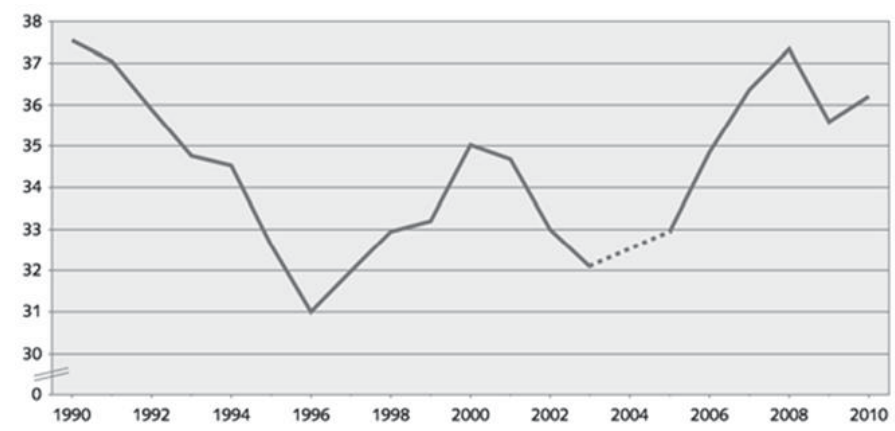

Figure 9: Hotels and Health Establishments: Evolution in overnight stays from 1990 to 2010, in millions

Source: Strauss et al. 2011, p. 11

The figure 9 represents the equilibrium for overnight stays in Switzerland that decreased between 2008 and 2009.

Table 1: Tourism indicators

\begin{tabular}{|c|c|c|c|}
\hline \multicolumn{4}{|l|}{ Main tourism indicators } \\
\hline & 2000 & 2008 & 2005 \\
\hline \multicolumn{4}{|l|}{ Supply (beds) ${ }^{1}$} \\
\hline Hotels and health establishments & 264495 & 270487 & 273974 \\
\hline \multicolumn{4}{|l|}{ Demand: arrivals in '000 } \\
\hline Hotels and health establishments & 13894 & 15997 & 15564 \\
\hline Campsites & $\ldots$ & 834 & 923 \\
\hline Youth hostels & & 490 & 476 \\
\hline
\end{tabular}

Demand: overnight stays in '000

\begin{tabular}{lrrr}
\hline Hotels and health establishments & 35020 & 37334 & 35589 \\
\hline Foreign guests in \% & 58 & 58 & 57 \\
\hline Campsites & $\ldots$ & 2987 & 3267 \\
\hline Foreign guests in \% & $\ldots$ & 48 & 46 \\
\hline Youth hostels & 804 & 978 & 946 \\
\hline Foreign guests in \% & 46 & 45 & 42 \\
\hline
\end{tabular}


The following demand and supply figure is constructed using the values presented in Table 1.

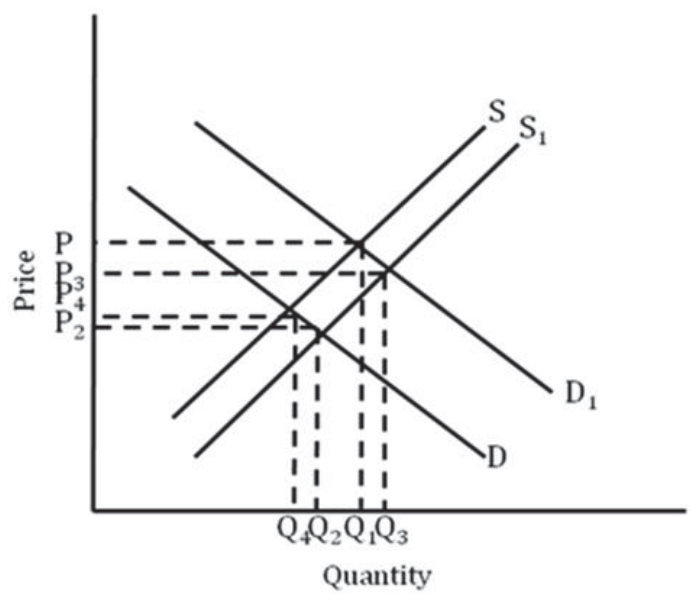

Figure 10: Demand and supply in the tourism sector in Switzerland

Source: designed by author

The figure 10 shows the market for the hotel beds in Switzerland that indicates the demand and supply for tourism as a whole. On the left axis there is the price and on the right quantity demanded. The $D_{1}$ curve represents the demand for hotel beds in 2008. $S_{1}$ curve shows the supply in 2008. $D_{2}$ curve shows the demand in 2009 and $S_{2}$ shows the supply in 2009. There are two equilibriums. At first equilibrium, $D_{1}$ and $S_{1}$, the price is at $P_{1}$ and quantity demanded at $Q_{1}$. At second equilibrium, $D_{2}$ and $S_{2}$, the price level is at $P_{2}$ and quantity at $Q_{2}$. Therefore it can be seen from the figure that the 2008-2009 recession had a negative effect on the tourism sector in Switzerland, because as demand decreased, supply increased. This can be explained as a result of the expensive nature of Swiss tourism deterring tourists, while the market renovations within Switzerland expanded and continued to develop. Therefore the total revenue from tourism decreased. Official values show that the total revenue indeed decreased (STF, 2012).

Once the demand for tourism in Switzerland decreased, the price decreased accordingly. This may be a reason for an increase in demand in 2010.

\subsection{Global climate change effect on the tourism industry in Switzerland}

There are also exogenous causes affecting the Swiss tourism market, such as global warming for example. It is possible that other factors, such as climate change, may have been a cause of the decline of the tourist industry.

Global warming is a declared scientific fact (Climate change, 2014). Global warming is the constant rising of the Earth's atmosphere (Global Warming: News, 2014). It creates the melting of ice and snow. In Switzerland the effect of global warming can be seen through melting glaciers.

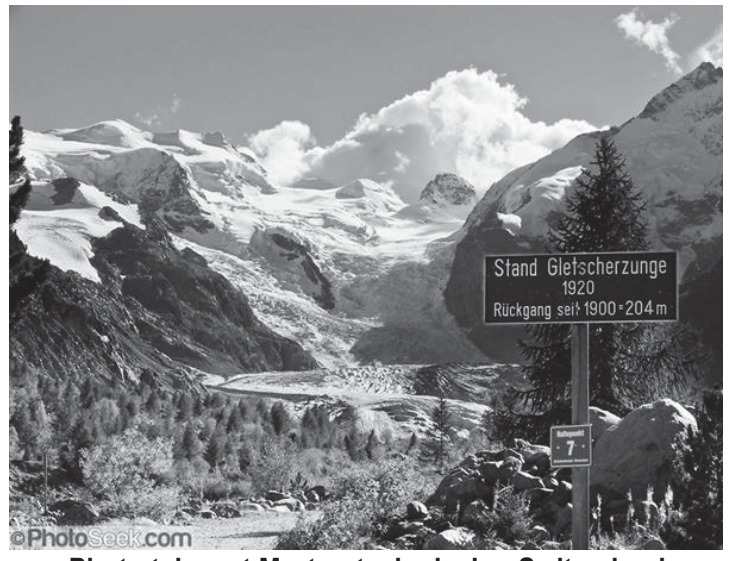

Photo taken at Morteratsch glacier, Switzerland 
The picture above shows the effect of global warming on Swiss glacier "Morteratsch". The sign indicates that in the year 1920 , the glacier was at the point of the sign.

Global warming is a constant rise in the temperature of the Earth (New Mexico Solar, 2013). Global warming negatively affects the winter tourist industry but can have a positive effect on summer tourism in Switzerland. In winter, the opening times of famous resorts are later every year due to hot conditions and melting snow. Therefore the revenues of the ski resorts might be decreasing every year. On the other hand, in summer, warmer conditions may be more attractive to the tourists for mountaineering as the season is lengthened. Global warming affects the famous ski resorts in Switzerland. It forces earlier closing of the season and later opening of the season (Figure 11).

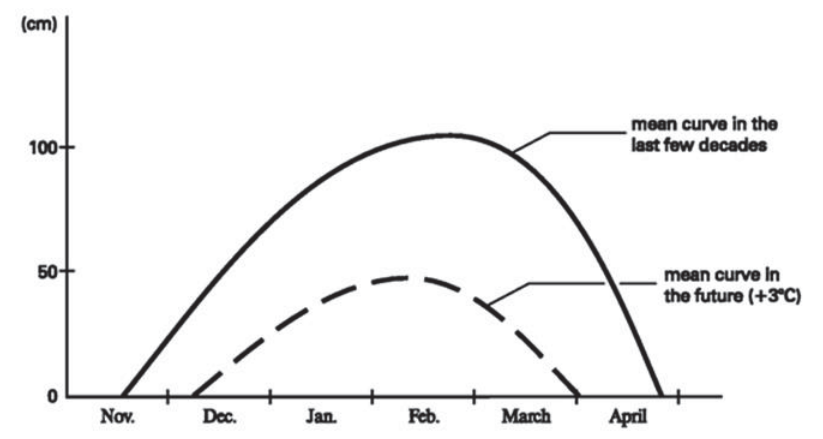

Figure 11: Mean curve in the decades

As can be seen from the opening times of the ski resorts in canton Grisons, the opening times of the ski resorts shrank in the past 50 years. Therefore this could lead to fewer people having a chance to visit the resorts and will therefore make the amount of revenue made from winter tourism go down.

\subsection{Production Possibility Frontiers}

Production possibility frontier is a curve that depicts maximum possibilities for two goods given a set of inputs (Blink \& Dorton, 2012). This is a purely theoretic idea. The following figure 12 shows an effect of global warming on skiing and industry.

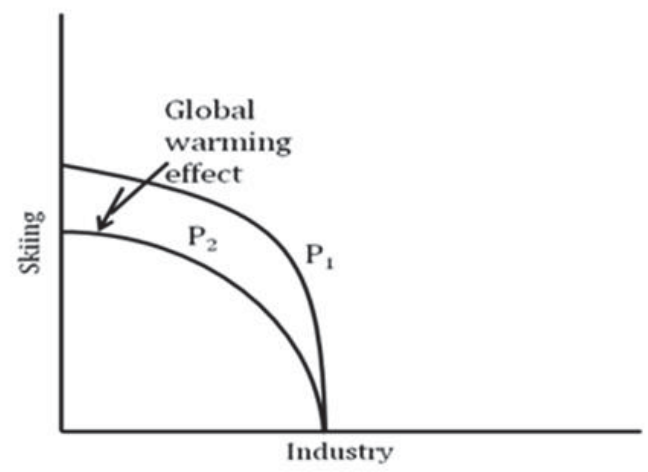

Figure 12: Production possibility frontier for skiing and industry

Source: designed by author

The effect of the global warming results in a change of the curve. The original curve is $\mathrm{P}_{1}$ and the curve showing the effect of global warming is $\mathrm{P}_{2}$. Global warming likely affects certain factors of production such as land. The corresponding impact on the PPF curve is indicated.

The global recession may also make the total output go down and this is represented by the following production possibility frontier curve. 


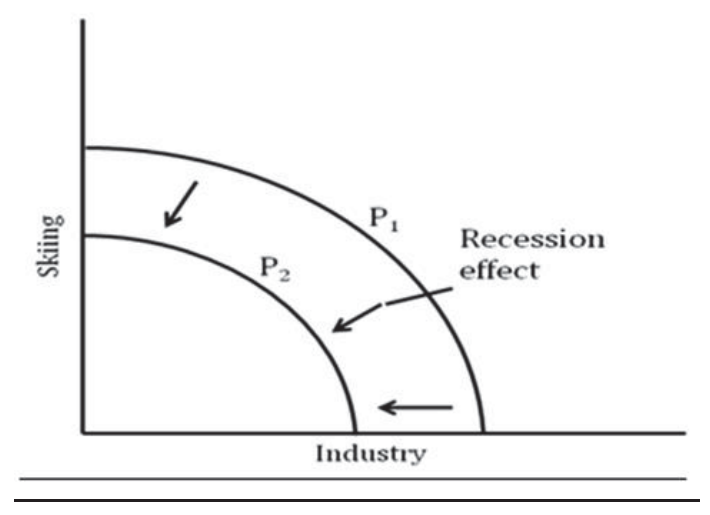

Figure 13: Production possibility frontier for skiing and industry in recession

Source: designed by author

Original curve is $P_{1}$ and curve showing the production possibility frontier in a recession is $P_{2}$. Therefore it can be seen that the output shrank due to the recession.

\subsection{Case study of a ski and snowboard shop in St. Motitz during the recession}

A study of a local sport shop in St. Moritz, Switzerland was undertaken. A sports shop was chosen as an indicator of tourism because the tourists usually rent ski equipment. The sports shop is called Ivo's Sport Shop. There was a short interview carried out with the shopkeeper Ivo Caratsch. He explained that the number of days that skis were rented overall (of all models) decreased in 2008 by 60 from the prior year in 2007. He also explained that in this year the same people rented the skis for longer periods of time, rather than many people renting skis for shorter periods. Unfortunately, the shopkeeper did not specify the changes in revenue. However, he noted that the revenue had decreased and that if the same had happened in 2009 he would probably have gone out of business.

\section{Conclusion}

\subsection{Overall conclusion}

From the data collected and analysed it can be concluded that the global recession significantly affected the tourism sector in Switzerland, but this was not the only factor causing the decline.

Although global recession without a doubt played a part in the downturn, this may have been overshadowed by several factors that might have affected a decrease in demand for the tourism in Switzerland. These include foreign exchange and other exogenous factors, such as global warming.

Global warming might have had an effect on the decreased demand for tourism. However, the measurement of this effect can only be theoretical as there are several limitations to this investigation. Even though the opening times of ski resorts were affected, it is very difficult to predict the number of people visiting the resort as there might be more people going on holiday in January than normal. In addition, global warming might have a positive effect on the tourism sector in the summer due to higher temperatures. Therefore, the true relative effect of global warming could not be evaluated.

The evaluation of the effect of currency value had fewer limitations. Analysis shows there is a positive correlation between the value of currency and the number of visits to Switzerland. As the value of the Swiss franc went up, the demand for tourism decreased. However, after 2009, despite the fact that currency value appreciated against most of the currencies (dollar), the demand for holidays from Americans had risen in 2009. Therefore the currency value does not fully explain the decrease in demand for tourism in Switzerland.

The global recession, therefore, most truly explains the decrease in demand for tourism in Switzerland. The recession had the biggest influence on the exchange rates in 2007-2009, which had some effect on the tourism demand as the CHF appreciated most at that specific period. Euro and dollar are the currencies primarily affected as most of the people that visit Switzerland come from the countries that use these currencies. Due to deflation in other countries, people might have chosen other destinations in preference to Switzerland. And finally, consumer confidence was lowered in global recession due to media. 
Considering all evaluations, it can be stated that hypothesis was proven and global recession adversely affected Swiss tourist sector. This is supported by the evidence that the demand for tourism decreased during the global recession.

Nevertheless, the global recession did not have a large effect on the tourism sector long term, since it only affected Switzerland in 2008-2009. After that year the demand for tourism started to rise again.

\subsection{Limitations}

The primary limitation is that statistics that were used for analysis are corrected and updated some years after the data has been published.

There is an unresolved question concerning global warming. It is how did the number of tourist stays in Switzerland in summer compare to winter stays as the data used was for the whole year. Therefore the true effect of global warming could not be determined.

\subsection{Further possible investigation}

For a deeper investigation of the effect of global warming, a breakdown of summer and winter hotel stays could be used to more accurately evaluate the effect of global warming.

A further investigation could be carried out by comparing all of the currencies used by tourists that visit Switzerland from other countries, not just the major ones.

Cities in other parts of Switzerland such as Zurich and Geneva could be examined. As they have no mountains there, the effect of global warming would not be a factor. Therefore hotels in big cities of Switzerland may reflect a more accurate effect of recession than Switzerland as a whole.

\section{References}

Blink, J., \& Dorton, I. (2012). Economics Course Companion. Oxford: Oxford University Press.

Brigham Young University-Idaho. (2011). Unemployment and Inflation. [Online] Available: https://courses.byui.edu/ECON_151/ Presentations/Lesson_05.htm

Campbell, R. M., \& Stanley, L. B. (1996). Microeconomics: Principles, Problems, and Policies. New York: McGraw-Hill, Inc.

Central bank intervenes with euro exchange rate. (2011). [Online] Available: http://www.swissinfo.ch/eng/central-bank-intervenes-witheuro-exchange-rate/31069308

Climate change: How do we know? (2014). Global Climate Change: Vital Signs of the Planet. [Online] Available: http://climate.nasa.gov/ evidencel

Deflationary Policies. (2011). Biz/ed. [Online] Available: http://www.bized.co.uk/reference/diagrams/Deflationary-Policies

Double-Dip Recession. (2014). Investopedia. [Online] Available: http://www.investopedia.com/terms/d/doublediprecession.asp

Econ, D. (2002). What are business cycles and how do they affect the economy. [Online] Available: http://www.frbsf.org/education/ publications/doctor-econ/2002/may/business-cycles-economy

EconomyWatch Content. (2010). Switzerland Economic Structure. [Online] Available: http://www.economywatch.com/world_economy/ switzerland/structure-of-economy.html

Glanville, A., \& Glanville, J. (2011). Economics from a global perspective. Winkleigh: Glanville Books Ltd.

Global Warming: News, Facts, Causes \& Effects. (2014). [Online] Available: http://www.livescience.com/topics/global-warming/

Holroyd, S. (2012). International Baccalaureate Economics Higher Level. Oxford: OSC Publishing.

Keppel, C., \& Wörz, J. (2010). The Impact of the Global Recession in Europe: The role of international nrade. In P. Backe, E. Gnan \& P. Hartmann (Eds.), Contagion and Spillovers: New Insights from the Crisis, SUERF Studies 2010/5. Vienna, Brussels: Larcier.

Kuepper, J. (2012). Swiss Currency: How to Invest in \& Buy Swiss Francs. [Online] Available: http://internationalinvest.about.com/od/ foreigncurrencies/a/Swiss-Currency-How-To-Invest-In-And-Buy-Swiss-Francs.htm

Most Expensive Countries to Live in. (2014). Aneki. [Online] Available: http://www.aneki.com/expensive.html

New Mexico Solar Energy Association (2013). Global Warming FAQ. [Online] Available: http://www.nmsea.org/Curriculum/Primer/ Global_Warming/fossil_fuels_and_global_warming.htm

Rosenberg, $\bar{M}$. (2014). Sectors of the Economy. [Online] Available: http://geography.about.com/od/urbaneconomicgeography/ a/sectorseconomy.htm

Strauss, Y., Bergen, L., \& Stalder, S. (2011). Swiss tourism statistics 2010. Neuchâtel: Federal Statistic Office.

Strauss, Y., Bergen, L., \& Stalder, S. (2013). Swiss tourism statistics 2012. Neuchatel: Federal Statistic Office.

Substitute goods. (2013). Business Dictionary. [Online] Available: http://www.businessdictionary.com/definition/substitute-goods.html 
Swiss Tourism Federation. (2012). Swiss tourism in figures 2011: Structure and Industry Data. Bern: Länggass Druck.

The Role of International Trade. (2010). [Online] Available: http://www.i4ide.org/people/ woerz/docsjw/Keppel-Woerz_Aug2010.pdf United Nations Development Programme. (2013). Summary Human Development report. New York.

United Nations World Tourism Organization: Tourism Highlights. (2009). Madrid: United Nations World Tourism Organization.

Ziogas, C. (2008). Economics for the International Baccalaureate Diploma Standard and Higher Level. Oxford: Oxford University Press. 